\title{
Web Usability and User Trust on E-commerce Websites in Pakistan
}

\author{
Rohail Shehzad \\ CS and IT Department \\ University of Lahore Pakistan \\ Zulqurnan Aslam \\ CS and IT Department \\ University of Lahore Pakistan
}

\author{
Nadeem Ahmad \\ CS and IT Department \\ The Superior University, Lahore Pakistan \\ Muhammad Waseem Iqbal \\ CS and IT Department \\ University of Lahore Pakistan
}

\begin{abstract}
Web usability is an integral part of e-commerce. Users are less prone to the websites which are difficult to navigate and slow in response time. E-commerce business is growing aggressively on daily basis, but lack of user trust can impede this growth. Success of online business is largely dependent on getting user's trust. There are different techniques and models to measure web usability and user trust level, but they are not covering all aspects of web usability. So we proposed a new enhanced SUPR-Q model with six (6) parameters, such as Usability, Effectiveness, Efficiency, Learnability, Satisfaction and Security. We performed an experiment with one hundred twenty (120) participants to measure the web usability and user's trust on two famous e-commerce websites of Pakistan (daraz.pk \& homeshopping.pk). We divided our participants into two equal groups, such as Random and Regular group on the basis of their previous shopping exposure. Our results shows that usability score of Regular group who did shopping most frequently were better than the Random group which was less exposed with shopping experience. Regular group was more satisfied from both websites with the score of $46.8 \%$ on daraz.pk and $44.8 \%$ on homshopping.pk as compared to Random group. Both groups showed higher usability score on daraz.pk which was $45.2 \%$ in case of Regular group and $40 \%$ in case of Random group due to the higher effectiveness and efficiency of web interface. The overall results showed that trust on e-commerce website plays vital role in user's satisfaction and purchasing.
\end{abstract}

Keywords-Web usability; e-commerce; user trust; Pakistan; random; regular

\section{INTRODUCTION}

The technological development, such as websites have become an essential business platform for buying, selling and distributing products. This includes sharing of products between organizations to customers, organizations to organizations and customers to customers. This has brought ecommerce to an entirely new level where people expect more from these websites [4, 7]. E-commerce websites are always great improvement for your business without any kind of physical boundaries. It is therefore important that website should be easy to use; else it will put bad impact on the customers[4]. For the e-commerce websites, 'user' is the most important factor for the success of a business or failure of the business, so user should be the main focus point while making these websites [24]. These e-commerce websites are growing very fast but they don't follow the proper standards that is the reason still today, people don't trust these websites in Pakistan. They lack some usability standards which should be followed while making the websites.

According to the Jakob Nielsen [30], Usability is a quality attribute that assesses how easy user interfaces are to use. The word "usability" also refers to methods for improving easeof-use during the design process [8]. The ISO 9241 standard recommends that usability metrics should include: [2]

1) Effectiveness: How effectively user completes the specific goal.

2) Efficiency: What resources are consumed to attain specific goal.

3) Satisfaction: What is the user feedback? How much he is satisfied with the system.

Abran [1] produced enhanced model of usability. They added two more essentials in the standard ISO usability model. They added learnability and security. Learnability means, time required to learn how many time he/she acquired the help. Security as name suggests is a very important factor in ecommerce websites.

Trust is very crucial element in e-commerce websites. If people trust you, they will do business with you [28]. Strong trust level will lead toward the purchase of the item. When consumers don't see the famous brands on the websites they will not trust the websites and eventually they will not make any purchase [27]. The role of trust becomes more important in e-commerce sites because both partners don't know each other and they may be sometime located in unknown places [14]. The objective of this paper is to present a study that evaluated a relationship between usability of the website interface design and the level of trust of potential customer on e-commerce websites in Pakistan. To accomplish this task two well known e-commerce websites, successfully running in Pakistan were selected for the evaluation. We evaluated the hypothesis that higher security level enhances usability and satisfaction level.

In this paper we conducted an experiment with one hundred twenty (120) participants that were divided into two (2) equal 
groups named as Random group and Regular group. Each group performed the tasks given by us in twenty (20) minutes on each website after that a post-experiment questionnaire was filled online and responses of this questionnaire were collected. After filling the questionnaire, a feedback session was conducted in which participants gave useful suggestions and feedback about these websites.

Section 2 of this paper presents the background and related work about the web useability and trust of e-commerce websites. Section 3 describes the enhanced usability framework and Section 4 demonstrate the research methodology related to our experiment. In Section 5 detailed results are discussed while Section 6 describes the observations and findings. Section 7 have some of our design recommendations related to website interface design and Section 8 concludes our contribution along with future work.

\section{BACKGROUND AND RELATED WORK}

An easy to use website is more effective and preferable when it has high usability [16] [6]. Though there is continuous growth in e-commerce and many companies are converting to e-commerce business. But they are reporting problems regarding attracting new customers and retaining existing one. They are facing big challenges in converting online purchases to real purchases [15] [10]. A strong relationship between user performance and usability has always been supported even ISO [22] emphasizes on the performance of website. Further Nielsen and Levy [31] stated that user performance is one of the important determinants of usability.

The major issue with online purchasing is trust. Less trust level leads towards less purchase. Many researchers have already worked on better understanding of user trust level on e-commerce websites. Gustavsson did study to get better understanding of user trust in e-commerce. Gustavsson and Johansson [20] choose a survey as their research strategy and primary data was collected through questionnaire. Questionnaire was handed out to people of the age from eighteen (18) to above and two hundred (200) participants were chosen for this experiment. The security and privacy are the main factors which effect trust of consumer to purchase online.

Another group of researchers Christine Roy et al [14] did some research on the fact that website usability has direct impact on the trust of the supplier. They have suggested that quality of interface is outcome of the initial trust establishment. They took sixty-six (66) subjects and asked them to perform some predefined book purchasing tasks from different kind of fourteen (14) websites having different kind of interfaces and then data was collected to evaluate the interface of the site and the level of trust on the websites. They noted that $31.8 \%$ of them had already made some purchases where as $53 \%$ was not willing to share their credit card information. However $82 \%$ participants think that making purchase online would simplify their task and will increase their efficiency. They found that four (4) usability factors out of five (5) have significant impact on trust of vendor. They concluded that usability of a website has significant impact on the establishment of the trust.

Fogg et al [17] evaluated the credibility of the websites. They took more than two thousand five hundred (2500) people to evaluate two (2) big websites of health domain and then they tried to find out what people think about the credibility of these websites by analyzing the comments of people. The purpose of study was to investigate what people notice when they are asked to evaluate the credibility of a website. In the study $46.1 \%$ people gave the comments about the website design and look. Next important thing was website information structure and the information focus. Study shared the comments of the participants about the top 18 areas of the websites where people noticed while evaluating the websites credibility. In addition to analyzing the comments as a whole, they also analyzed comments for a specific domain. For e-commerce sites, people gave different comments. In those comments popular name and reputation of vendor were more important (in $25.9 \%$ of comments) than the overall average $(14.1 \%)$. Also, comments about customer service were more frequent $(16.7 \%$ v. $6.4 \%)$.

Rofiq and Mula [35] did survey for the Indonesian ecommerce websites and they measured the customer's trust by analyzing the effect of vendor's ability and integrity. The outcome of the study stated that vendor's integrity has positive and substantial effect on the Indonesian customer's trust.

Lee and Koubek [24] examines the effects of usability and web design attributes on user preference for e-commerce web sites. They examined the relationship between the perceived usability before actual use and effect of design attributes on user preferences for e-commerce websites. They also measured the task completion time. Nine online bookstore websites used by ten participants to perform this task. The outcome of the study was, pre-use usability and task completion time were correlated. Organizational structure and layout had great impact on user preference than its aesthetic aspects. Further different design attributes on user preference has also been observed.

WebQual is a method for assessing the quality of the website by Loiacono et al [26]. It is a method which has been used in various domains. Barnes and Vidgen [4] measured the assessment of e-commerce website quality using WebQual method, to access online bookshops. This method has been developed iteratively through applications in various domains. This method converts the qualitative customer assessments into quantitative metrics that can be useful for different decision making.

Rahman et al [34] highlighted the main issue which is restricting the people from purchasing online. Sixteen very famous e-commerce business websites are taken for the experiment from Pakistan. They took participants from the age ranging from fourteen (14) years to sixty (60) years from Pakistan. They applied Nielson's usability heuristics and some recommendation and suggestions were given on the basis of the results of the survey. They showed that current websites are not following proper usability standards defined by Nielson and people of Pakistan use these websites only to view the new trends, prices and description of products and they actually don't make any purchase through these websites.

Jones et al [23] measured the trust, attitude towards the web, experience with the web and web usability. They found that person's increased web experience also increases the trust of users on the websites. 
Similarly Casaló et al [9] presented a work analysis to measure the two concepts: trust and satisfaction.

Hampton-Sosa and Koufaris [21] examines the impact of website appearance and usability on customer's trust of online company.

\section{ENHANCED USABILITY FRAMEWORK}

Usability is very vital for a website to survive, people will leave the website if they could not find what a company offer, on its home page. One big reason of bad interface design for a website is the lack of understanding about how the user will surf the website for information [13]. According to Nielsen - The word usability also refers to methods for improving ease-of-use during the design process [30]. According to him usability contains five (5) quality components: Learnability, Efficiency, Memorability, Errors and Satisfaction. The perception of usability often affected by user characteristics such as age, gender, education and technology skill level. Usability also affected by cultural differences like use of colors and animations [5].

ISO 9241 is a very diverse standard from International Organization for Standardization (ISO), which covers the ergonomics of Human Computer Interaction (HCI). Its key components are effectiveness, efficiency and satisfaction [2].

Different researchers proposed different models, like Abran et al [1] purposed modified version of ISO 9241. So our proposed model is based on ISO 9241 and Abran and Khelifi model and it is shown in Fig. 1 and it is our selection criteria for this decision.

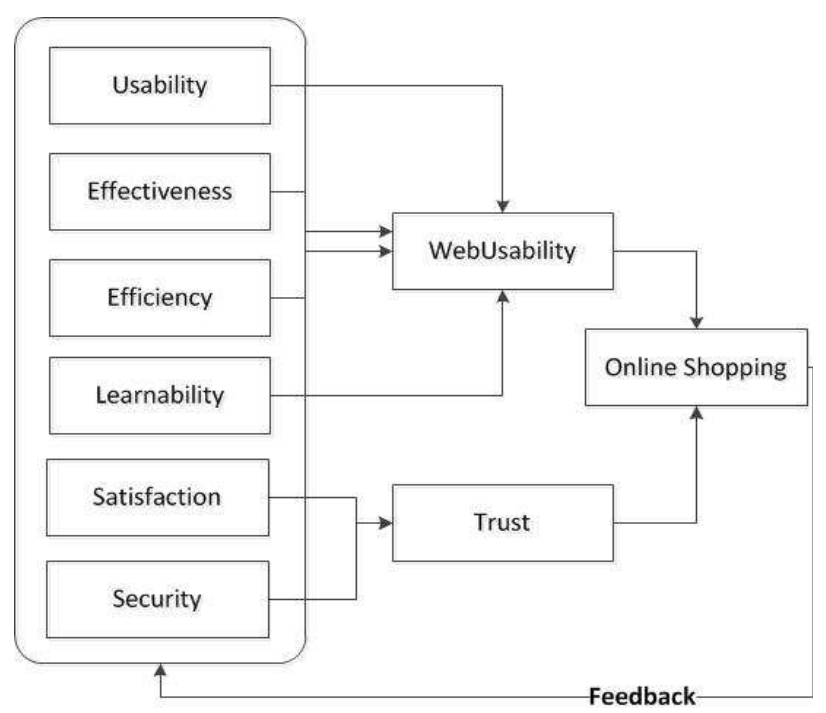

Fig. 1. Enhanced usability framework.

Our proposed enhanced usability framework consists of the six (6) elements:

Usability: How easy to use a product.

Effectiveness: How effectively user complete the desired task.

Efficiency: How efficiently user complete task with the use of minimal resources.
TABLE I. CATEGORIZATION OF PARTICIPANTS

\begin{tabular}{ccccc}
\hline & Online Shopping & Male & Female & Total \\
\hline Random Group & $\geq 1 \& \leq 3$ & 45 & 15 & 60 \\
Regular Group & $>3$ & 45 & 15 & 60 \\
\hline
\end{tabular}

Learnability: How easily user can learn the system.

Satisfaction: How much user is satisfied after using the system and what is their feedback.

Security: What protocols are implemented for securing the user information, privacy and financial transaction.

Usability, Effectiveness, Efficiency and Learnability leads towards the website usability and satisfaction and security leads toward the customer's trust on the website. Our proposed model is more advance and comprehensive because it includes both process-related and product-related usability characteristics.

\section{Methodology}

The experiment was performed in three steps. First step was about the filling of pre-experiment questionnaire to get participant's basic information. Then in step two some predefined tasks were given to the subjects and they have to complete those tasks in twenty (20) minutes. In the last step they have to fill out the post experiment questionnaire and they have to give suggestions, feedback, and design recommendations for the websites. To measure the web usability and user trust experiment was conducted on the two e-commerce websites of Pakistan daraz.pk and homeshopping.pk. These two websites are most popular and categorized as top ranked for shopping in Pakistan.

\section{A. Participants}

As described earlier, the purpose of this study was to evaluate the usability and trust of peoples on e-commerce websites in Pakistan, so the study focuses on those people that have used these websites at-least once for online shopping. The users participated voluntarily in the study. We excluded some participants on the basis of pre-task questionnaire. The pre-task questionnaire helped us to identify which users can participate in the activity. Forty-five (45) participants were discarded out of one hundred sixty five (165).

Twenty-five (25) participants were found that do not perform online shopping once.Ten (10) users were confused while performing the tasks and left the activity incomplete. Three participants with vision problems were also excluded. Finally, seven participants were excluded for other reasons, that is, to maintain gender ratio and an age between sixteen (16) and sixty (60) years. As described earlier, one hundred twenty (120) participants were chosen to participate in the experiment and divided into two equal groups named Random Group and Regular Group. Random group are those participants who performed less than three times shopping in the last year. Those participants who performed shopping on these websites regularly i.e. more than three times in a year are categorized under Regular group. Each group of participants consists of forty five (45) male users and fifteen (15) female users. The details about the groups are given in Table I. 
The experiment was conducted to evaluate the effectiveness, efficiency, satisfaction and user trust on these websites. This study did not require the participants to complete the purchase of a product by submission of credit card information or using checkout method. Different surveys on e-commerce websites shows that the usability and the usefulness of a website can be determined without actually purchasing a product or a service $[3,11,12,19,18,25,32,33]$.

In our experiment the number of women were less than the number of men due to the fact that its quite difficult to access women in Pakistani society as most of them do not want to share their identity. In our experiment the male-to-female ratio was similar among the selected groups.

\section{B. Tasks}

The participants were given a small fifteen (15) minutes presentation on multimedia to explain the purpose of the research and some explanation about pre and post experiment questionnaire. They were also given some time to get acquainted to the system. There were total eight (8) tasks which they have to perform on the given two websites, other than filling the pre-experiment questionnaire and post-experiment questionnaire. Daraz.pk and Homeshopping.pk are very famous e-commerce websites of Pakistan to sell every type of goods like jewelry, mobile, computer, musical instruments and garments etc.

In the experiment, task one was to sign up/in the website. They have to make accounts on the websites. Second task was to find a perfume of their own choice. Third task was to find any laptop of their favorite brand and add that laptop into cart. Fourth task was regarding the comparison of the products available on the websites. They have to find two different mobiles to compare their specifications and finally add one of them in shopping cart.

Step five was to remove the products from the cart those were added in step three. We performed experiment before the checkout process to avoid the actual order placement and processing. In step six participants were ask to find how to acquire help in these websites. In step seven they have to search for the return policies and in last step they have to sign out from the system.

After these tasks a post experiment questionnaire was given online for each website and they have to fill that form then a short interview was conducted with each participants to get his feedback and suggestions. The suggestions and feedback of the users were noted. The interviews were very helpful for open-ended qualitative feedback about missing features and suggestions to make the process easier, robust, and user friendly.

\section{Experimental Setup and Procedure}

This study experiment was carried out in the computer lab of The University of Lahore, Pakistan in two different sessions where sixty (60) users participated in each lab session. In lab, all computers were homogeneous with respect to system specification and operating system. Complete experiments were conducted in three weeks. In 1st week, pre-experiment questionnaire were given to all participants. Questionnaires were online, where each user can submit only one response against his/her email id. In this pre-experiment questionnaire there were total six (6) questions to know the user's basic information, their daily computer usage and number of times they performed shopping in last year (Fig. 2).

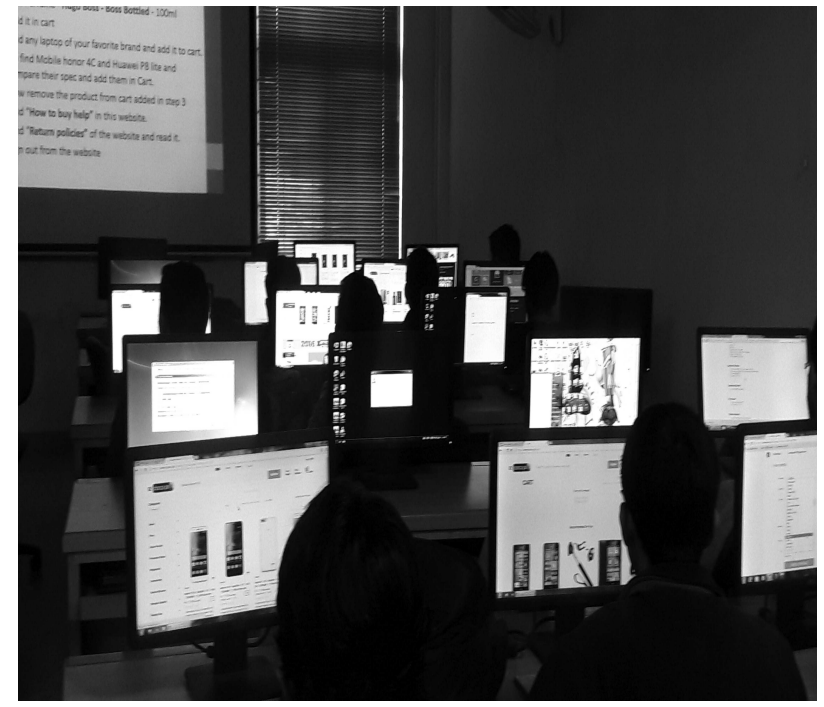

Fig. 2. Users are performing experiment in the lab.

The first session regarding online shopping was conducted in second week. In first session random group performed the experiment in lab. As mentioned earlier, there were total eight (8) tasks involved in online shopping. Each lab session was one (1) hour and (30) minutes long where twenty (20) minutes were given for performing task on website 1 . Then fifteen (15) minutes to fill out the post experiment questionnaire and last five (5) minutes were given for getting suggestions/feedback from end users. After the break of ten (10) minutes participants were asked to repeat the steps for website 2. First they performed task on daraz.pk and then on homeshopping.pk.

All the participants were informed in the beginning of the experiment that no assistance will be provided, and if someone thinks that he/she will not be able to perform these tasks, he/she can leave the lab after informing the mentor and don't fill the form, to make the experiment transparent and unbiased.

Second session was conducted after one week and in this session Regular group performed the experiment. A small change in this session is that this group performed task firstly on homeshopping.pk and then on daraz.pk.

\section{Evaluation}

The end user trust level and web usability were evaluated on the basis of task completion time and our proposed enhanced Standardized User Experience Percentile Rank Questionnaire (SUPR-Q). The SUPR-Q is a rating Scale to measure perceptions of usability, trust, credibility, appearance and loyalty for websites [36]. This scale gives relative ranking in terms of percentage, so fifty (50) is average percentile rank score for SUPR-Q. The SUPR-Q has thirteen (13) items, twelve (12) items have five (5) different choices while one (1) item has eleven(11) different response items. The global reliability of SUPR-Q is 0.94 [39]. Our proposed questionnaire 
is an enhanced form of SUPR-Q having twenty three (23) items with six (6) parameters such as usability, effectiveness, efficiency, learnability, satisfaction and security. All items have five choices having equal logical distance on likert scale. This enhanced model is used in this study because it covers all the important factors related to web usability and user's trust.

\section{Results}

Random and Regular groups performed experiment on both websites separately and filled the pre and post experiment questionnaires. To measure the performance of both groups on these websites the performance metrics are based on number of completed tasks and task completion time of each group. Results of this experiment are not only compared between groups but also compared with-in the groups.

Fig. 3 shows the average time (in minutes) per user of Random and Regular groups on both websites. Random group spends almost equal time on both websites while Regular group consumed less time on daraz.pk as compared to other website.

\section{Average Time Per User On Daraz.pk And Homeshopping,pk}

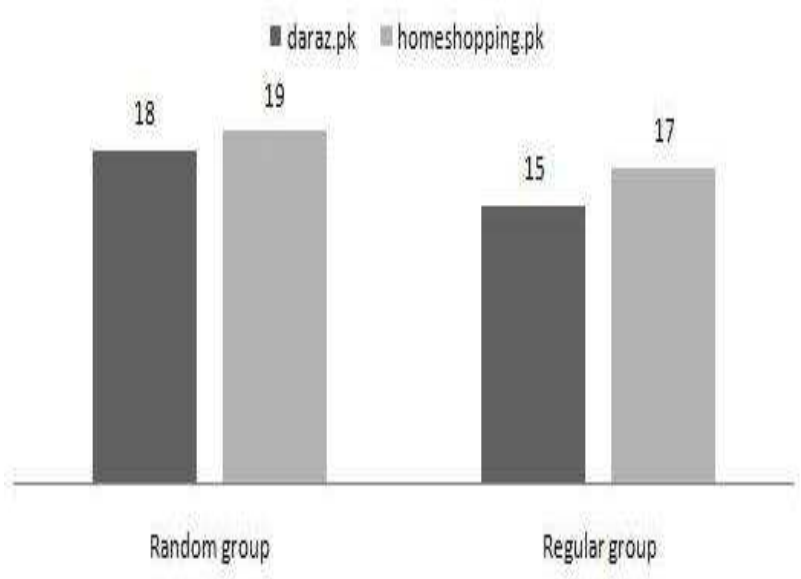

Fig. 3. Average time per user on both websites.

Average number of tasks completed per user are shown in Table II. Random group completed seven (7) tasks on daraz.pk and completed five (5) tasks on homeshopping.pk. On the other hand Regular group completed seven (7) tasks per user on daraz.pk and six (6) tasks on other website. Both groups followed the sequence of tasks given in section 4.2.

Effectiveness is calculated on the basis of number of tasks completed successfully. It is calculated using a simple equation of completion rate metric [29].

$$
\text { Effectiveness }=\frac{\text { Number of tasks completed }}{\text { Total number of tasks }} * 100 \%
$$

A study conducted by jeff sauro [38] on twelve hundred (1200) usability tasks shows that average task completion rate is $78 \%$. Our results of task completion rate with shown in Table II.
TABLE II. AVERAge Number of TAsks Per User on Both WEBSITES

\begin{tabular}{l|l|l|l|l}
\hline & Groups & Number of Tasks & SD & Effectiveness \\
\hline \multirow{2}{*}{ Daraz.pk } & Random & 7 & 1.41 & $81 \%$ \\
& Regular & 7 & 1.54 & $91 \%$ \\
\hline \multirow{2}{*}{ Homeshopping.pk } & Random & 5 & 1.76 & $62 \%$ \\
& Regular & 6 & 2.18 & $78 \%$ \\
\hline
\end{tabular}

Efficiency is measured on the basis of task time. The task time is calculated with a simple equation that is Time based efficiency.

$$
\text { Time Based Efficiency }=\frac{\sum_{j=1}^{R} \sum_{i=1}^{N} \frac{n_{i} j}{t_{i} j}}{N R}
$$

$\mathrm{N}=$ Total Number of tasks

$\mathrm{R}=$ Total participants

nij= Results of task $\mathrm{i}$ by user $\mathrm{j}$. It is one (1) if user successfully complete the task otherwise it is zero (0).

tij= Time spend user $\mathrm{j}$ to complete task $\mathrm{i}$.

Both groups showed the highest efficiency on daraz.pk but on homeshopping.pk the task completion efficiency of Random group is less than the Regular group. Results of both groups are shown in Fig. 4.

\section{Time Based Task Completion Efficiency}

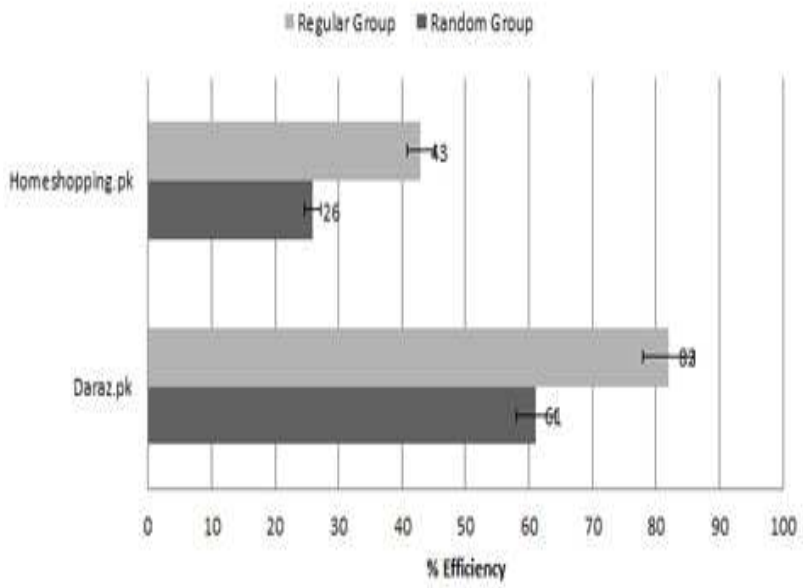

Fig. 4. Time based task completion efficiency.

Time based task completion efficiency of Random group was $61 \%$ on daraz.pk and $26 \%$ on homeshopping.pk. Regular group Showed high efficiency on both websites that were $82 \%$ and $43 \%$ respectively.

After performing the experiment all users were given the enhanced SUPR-Q questionnaire to collect their feedback about these websites. Same questionnaire were used for all type of groups so that their results can be compared. Fig. 5 and 6 shows the Z-Score to percentile rank of each group. Z-Score to Percentile Rank is Six-Sigma technique which means it ensure the highest quality output by reducing the defect after identifying the cause of deviations. [40]. It converts the score of likert scale into normal score. It is the only 
metric that includes variability in the scores and offer most precision because it uses the mean [37]. From questionnaire we measured remaining four parameters of the websites and those are usability, satisfaction, security and learnability. Fig. 5 and 6 shows the average Z-Score for remaining four parameters along their confidence interval. The score of daraz.pk was almost the double of homeshopping.pk.

\section{Enhanced SUPR-Q Overall Score for}

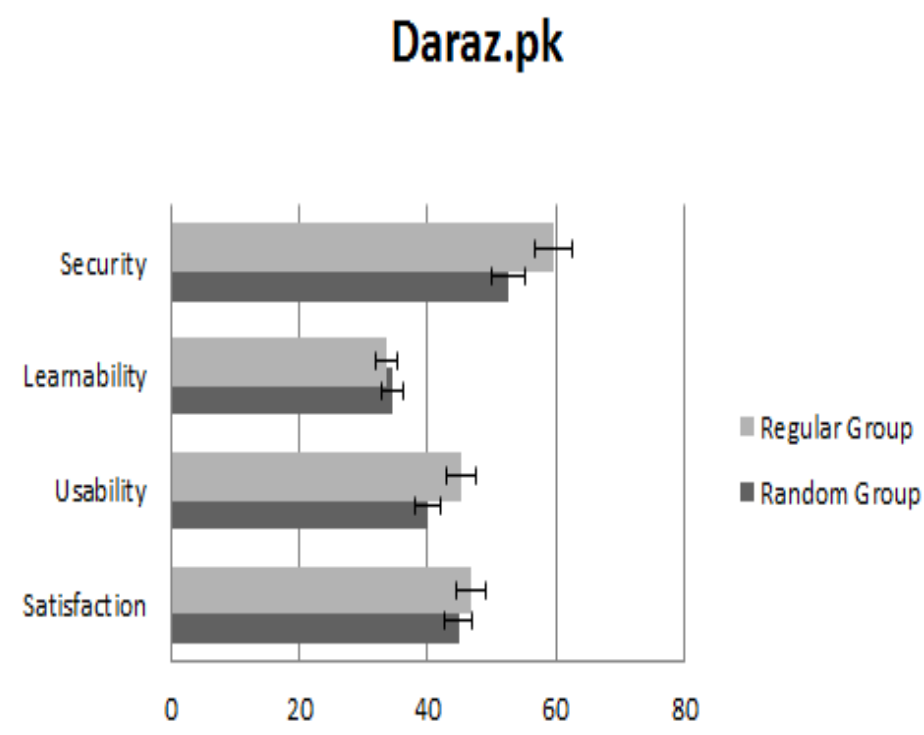

Fig. 5. Enhanced SUPR-Q Score Daraz.pk

Z-Score to percentile rank of Usability for Regular Group was 45.2 and for Random group it was 40 on daraz.pk. Using this score it is clear that Regular group was more satisfied with the usability of daraz.pk. Then we calculated same score for homeshopping.pk. Regular group score was 17.7 while random group scored 15.5. Scores of homeshopping.pk for Regular group was greater than other group but it was very low. Second we calculated Satisfaction score for both groups. 46.8 was the score for Regular group on daraz.pk and 19.1 on homeshopping.pk, whereas for Random group 44.8 was on daraz.pk and 17.5 was on homeshopping.pk. Again from the score it is clear that Regular group was more satisfied with the daraz.pk.

Our third calculated parameter was Security. Z-Score to percentile rank for Regular group was 59.6 on daraz.pk and 34 for homeshopping.pk. Random group score for daraz.pk was 52.7 and homeshopping.pk 33.3. Both group reacted almost same for the security of homeshopping.pk which was less secure. Learnability was our last parameter to calculate. Both websites scored almost same for the learnability. On Daraz.pk Regular group scored 33.6 and Random group scored 34.6 and on homeshopping.pk 27.6 was the score for Regular group and 26.7 was for Random group. So overall learnability score for daraz.pk was higher for both groups.

\section{OBSERVATIONS AND FINDINGS}

From user's interviews and feedback, it is observed that users were facing many challenges regarding usability and trust

\section{Enhanced SUPR-Q Overall Score for Homeshopping.pk}

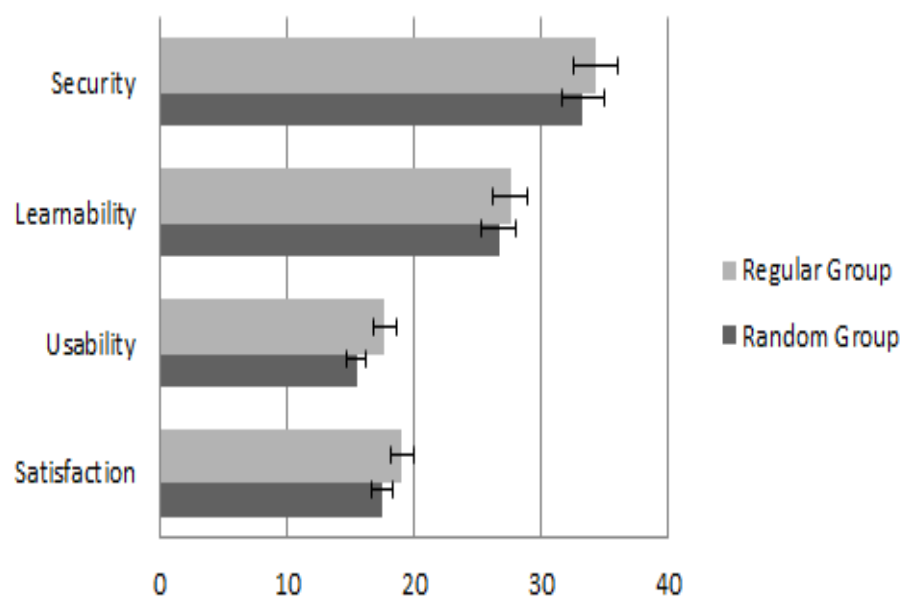

Fig. 6. Enhanced SUPR-Q Score Homeshopping.pk

on these websites. Major usability issues with these websites are shown in the Fig. 7.

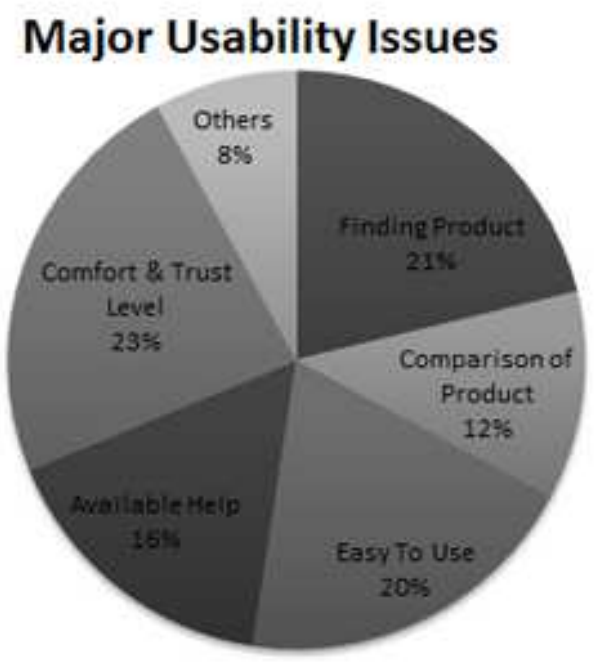

Fig. 7. Major usability issues.

These are some major observation that are observed from user's feedback.

1) The usability has direct impact on trust of user on that website. Higher usability will lead towards higher trust.

2) Usability of e-commerce websites of Pakistan is very poor. Color and font selection is not good. Searching on the websites has some issues, like no detailed results were there. No search suggestions were provided. Navigation of the sites are poor. No information regarding feedback, user reviews, rating of products, brand impression is available. 
3) Return Policy is not good like you can change product only if it has some defect or if it is not what you ordered, and if some websites have other options but that are very cumbersome.

4) People in Pakistan use these e-commerce websites only to see the latest trends and prices and don't do shopping because of trust level. People come on ecommerce websites, put orders in cart and at the end leave the site before completing the order because sign up process is not easy and people don't feel comfortable while giving credit card information and personal data even personal email.

5) People don't give reviews after buying products.

6) There should be compare feature on these website to compare different brand and products easily.

\section{OUR RECOMMENDATIONS}

Below are some of our recommendations for the websites which should be followed while making these websites:

1) Sign up process should be easy.

2) Add to cart and remove from cart should be simple.

3) Payment method should be secure. Use some third party security systems to get more trust of the customers.

4) If user have some items in the bucket and if he/she tries to close the browser then a pop up message can be shown that you have some items in cart, are you really want to close the window.

5) If cart price goes higher like more than three (3) thousand rupees then least important items should be filtered out for the user and system should give suggestion to the user that these are less important and these are more important items.

6) Once user put shipping address and other common fields then system should store that information for future use. No credit card related information should be stored. This will give user a little threat of privacy.

7) When a person completes order then make the review necessary so that people can provide their feedback. Reviews and rating is very helpful for other users to do shopping.

\section{CONCLUSION AND FUtURE WORK}

Internet is the integral part of everyone's daily life whether they are in home or in office. More and more businesses are moving towards online day by day. Website's usability has direct impact on the user's trust level but unfortunately there is a gap between customer's expectations and the results they get on e-commerce sites.

This study proposed a new enhanced SUPR-Q model to measure the web usability and user's trust level. Results of the study shows that overall usability score for daraz.pk was more reliable as compared to other website. On the other hand satisfaction of users was equally handed for both the websites. Our two parameters such as effectiveness and efficiency was accurately calculated from simple mathematical equations. Users showed highest results of effectiveness and efficiency on daraz.pk e.g $91 \%$ and $82 \%$.
After analyzing the experiment data, we found that as security level rating increases in both websites it enhances the usability and satisfaction level which shows that the hypothesis declared in introduction section is accepted. From user's interviews and feedback we highlighted many usability issues exists in both websites and we also gave some design recommendations for the future.

The experiment we performed was based on limited users sample; it might have been far productive and conducive to many more prospects, if it had been performed on large scale with bigger sample size. This experiment hails from six different parameters, but we have only been able to utilize two of them. This experiment may be expanded further by utilizing all the parameters individually compared with each other.

\section{REFERENCES}

[1] Abran A, Khelifi A, Suryn W, Seffah A (2003) Consolidating the ISO usability models

[2] Abran A, Khelifi A, Suryn W, Seffah A (2003) Usability meanings and interpretations in ISO standards, vol 11. Springer

[3] Agarwal R, Venkatesh V (2002) Assessing a firm's web presence: A heuristic evaluation procedure for the measurement of usability. Information Systems Research 13(2):168-186

[4] Barnes SJ, Vidgen RT (2002) An integrative approach to the assessment of e-commerce quality. J Electron Commerce Res 3(3):114-127

[5] Becker SA, Mottay FE (2001) A global perspective on web site usability. Software, IEEE 18(1):54-61

[6] Benbunan-Fich R (2001) Using protocol analysis to evaluate the usability of a commercial web site. Information \& management 39(2):151-163

[7] Berners-Lee T, Fischetti M (1999) Weaving the web. 1999. Orion Business, New York

[8] Bevan N (1995) Measuring usability as quality of use, vol 4. Springer

[9] Casaló LV, Flavián C, Guinalíu M (2010) Generating trust and satisfaction in e-services: the impact of usability on consumer behavior. Journal of Relationship Marketing 9(4):247-263

[10] Chen C (2003) An investigation of significant factors affecting consumer trust in e-commerce

[11] Chen C (2003) An investigation of significant factors affecting consumer trust in e-commerce

[12] Chen Ld, Gillenson ML, Sherrell DL (2004) Consumer acceptance of virtual stores: a theoretical model and critical success factors for virtual stores. ACM Sigmis Database 35(2):8-31

[13] Chi EH (2002) Improving web usability through visualization. Internet Computing, IEEE 6(2):64-71

[14] Christine Roy M, Dewit O, Aubert BA (2001) The impact of interface usability on trust in web retailers, vol 11. MCB UP Ltd

[15] Devaraj S, Fan M, Kohli R (2002) Antecedents of b2c channel satisfaction and preference: validating e-commerce metrics. Information systems research 13(3):316-333

[16] Donaire XS (2009) Don't make me think: a common sense approach to web usability. Item: Revista de biblioteconomia i documentació (50):134-135

[17] Fogg B, Soohoo C, Danielson DR, Marable L, Stanford J, Tauber ER (2003) How do users evaluate the credibility of web sites?: a study with over 2,500 participants. In: Proceedings of the 2003 conference on Designing for user experiences, ACM, pp 1-15

[18] Gefen D, Straub D, Boudreau MC (2000) Structural equation modeling and regression: Guidelines for research practice. Communications of the association for information systems 4(1):7

[19] Gefen D, Karahanna E, Straub DW (2003) Trust and tam in online shopping: an integrated model. MIS quarterly 27(1):51-90

[20] Gustavsson M, Johansson AM (2006) Consumer trust in e-commerce

[21] Hampton-Sosa W, Koufaris M (2005) The effect of web site perceptions on initial trust in the owner company. International Journal of Electronic Commerce 10(1):55-81

[22] ISO W (1998) 9241-11. ergonomic requirements for office work with visual display terminals (vdts). The international organization for standardization 45

[23] Jones K, Leonard LN, Riemenschneider CK (2009) Trust influencers on the web. Journal of Organizational Computing and Electronic Commerce 19(3):196-213 
[24] Lee S, Koubek RJ (2010) The effects of usability and web design attributes on user preference for e-commerce web sites, vol 61. Elsevier

[25] Liang TP, Lai HJ (2002) Effect of store design on consumer purchases: an empirical study of on-line bookstores. Information \& Management 39(6):431-444

[26] Loiacono ET, Watson RT, Goodhue DL (2002) Webqual: A measure of website quality. Marketing theory and applications 13(3):432-438

[27] Lowry PB, Vance A, Moody G, Beckman B, Read A (2008) Explaining and predicting the impact of branding alliances and web site quality on initial consumer trust of e-commerce web sites, vol 24. Taylor \& Francis

[28] matthew i (2014) container of truth. Lulu.com, URL https://books.google.com.pk/books?id=ouUNBAAAQBAJ

[29] Mifsud J (2015) Usability Metrics - A Guide To Quantify The Usability Of Any System

[30] Nielsen J (2003) Usability 101: Introduction to usability

[31] Nielsen J, Levy J (1994) Measuring usability: preference vs. performance. Communications of the ACM 37(4):66-75

[32] O'Donnell JB (2002) Assessment of the impact of web site design on consumer trust and the purchase decision. ACM

[33] Park JJ (2003) Understanding consumer intention to shop online: A model comparison

[34] Rahman M, Komal S, Khan A, Qamar T (2011) Usability and accessibility evaluation of pakistan's e-commerce sites. ARPN Journal of Science and Technology

[35] Rofiq A, Mula JM (2010) The effect of customers trust on e-commerce: A survey of indonesian customer b to $\mathrm{c}$ transactions. In: International Conference on Arts, Social Sciences \& Technology, Penang, Malaysia, pp 24-25

[36] Sauro J (2004) The Standardized User Experience Percentile Rank Questionnaire. http://www.suprq.com

[37] Sauro J (2011) How to interpret survey responses: 5 techniques. http://www.measuringu.com/blog/interpret-responses.php

[38] Sauro J (2011) What is a good task-completion rate? http://www.measuringu.com/blog/task-completion.php

[39] Sauro J, Lewis JR (2012) Quantifying the user experience: Practical statistics for user research. Elsevier

[40] Smith B (1986) Six Sigma: Strategy \& Methodology. http://www.esixsigma.org/

\section{AUthors' Profile}

Rohail Shehzad is an IT professional and Lecturer. He holds MS degree in Computer Science and he is a Software Engineer. He is working in the areas of Human Machine Interfaces for Deaf people. His research interests are in HCI, Gestural interfaces, Adaptive Interfaces, Virtual reality, Augmented reality and Visual design.

Zulqurnan Aslam is an IT professional and holds MS degree in Computer Science. He is an IT Development Manager and have more than 6 years of development experience in ERP systems and Web Developments and its architectures. He is researcher by passion and his research interests are in HCI, Semantic Web Mining and Adaptive Interfaces.

Nadeem Ahmad is the Head of CS \& IT department in The Superior University, Lahore (Pakistan). He has completed his Dual $\mathrm{PhD}$ from Politecnico di Torino (Italy) and University of Potsdam (Germany). He is working in the areas of Human Machine Interfaces for Deaf and Low-literacy users. His research work mainly focuses on natural user interfaces, social computing,usability barriers for low-literacy users, localization, accessibility and visual design.

Muhammad Waseem Iqbal is an assistant professor in the department of CS \& IT at the University of Lahore (Pakistan). He is Phd Scholar and working in the areas of adaptive user interfaces for mobile devices.

\section{APPENDIX}

\section{Pre-experiment Questionnaire}

1) What is your Gender?

- Male

- Female

- Prefer not to mention

2) What is Your Age?

- $16-24$

- $25-33$
- $\quad 34-42$

- $43-51$

- $\quad 52-60$

3) Did you ever perform online shopping once?

- $\quad$ Yes

- No

- Don't Know

4) If you have already perform online shopping, how many times you did shopping in past 1 year?

- 1-3 Times

- 4-6 Times

- $\quad$ More than 6 Times

5) How is your vision? (How do you see?)

- Normal

- $\quad$ Corrected to normal (use of glasses)

- I can see things better up close than far away

- I can see things better in the distance but not up close

- I generally can't see well

6) How often you use computer

- Daily 1 - 3 Hours

- Daily 4 - 6 Hours

- Daily More than 6 Hours

\section{Post-experiment Questionnaire}

Usability:

1) This website is easy to use?

- $\quad$ Strongly Agree

- $\quad$ Agree

- Neutral

- $\quad$ Disagree

- Strongly Disagree

2) I am able to find what I need quickly on this website?

- $\quad$ Strongly Agree

- Agree

- Neutral

- $\quad$ Disagree

- Strongly Disagree

3) I enjoy using this website?

- Strongly Agree

- $\quad$ Agree

- Neutral

- Disagree

- Strongly Disagree

4) It is easy to navigate within the website?

- $\quad$ Strongly Agree

- $\quad$ Agree

- Neutral

- $\quad$ Disagree

- Strongly Disagree

5) I found the website to be attractive?

- $\quad$ Strongly Agree

- $\quad$ Agree

- Neutral

- $\quad$ Disagree

- $\quad$ Strongly Disagree

6) The website has a clean and simple presentation?

- $\quad$ Strongly Agree

- $\quad$ Agree

- Neutral

- $\quad$ Disagree

- Strongly Disagree

7) Will it be helpful to communicate with online reviewers?

- Strongly Agree

- Agree

- Neutral

- Disagree

- Strongly Disagree 
Learnability:

8) Could you perform the comparison of the products given in the task list?

- Strongly Agree

- Agree

- Neutral

- Disagree

- Strongly Disagree

9) Do you think comparison of two products should be there on ecommerce websites?

- Strongly Agree

- Agree

- Neutral

- $\quad$ Disagree

- Strongly Disagree

Satisfaction:

10) I feel comfortable purchasing from this website?

- Strongly Agree

- Agree

- Neutral

- Disagree

- $\quad$ Strongly Disagree

11) This website keeps the promises it makes to me?

- $\quad$ Strongly Agree

- Agree

- Neutral

- Disagree

- Strongly Disagree

12) I can count on the information I get on this website?

- Strongly Agree

- Agree

- Neutral

- Disagree

- Strongly Disagree

13) Is Cost of the product important for you?

- Strongly Agree

- Agree

- Neutral

- Disagree

- Strongly Disagree

14) I will likely visit this website in the future?

- $\quad$ Strongly Agree

- Agree

- Neutral

- Disagree

- Strongly Disagree

15) Does it affect your trust when you see some famous brands on the website?

- Strongly Agree

- $\quad$ Agree

- Neutral

- Disagree

- $\quad$ Strongly Disagree
16) How likely are you to recommend this website to a friend or colleague?

- Strongly Recommended

- $\quad$ Recommended

- Neutral

- Not Recommended

- Not Recommended

17) Are you satisfied with the help available on the website?

- $\quad$ Strongly Agree

- $\quad$ Agree

- Neutral

- Disagree

- Strongly Disagree

18) If you like the product and brand, do you think website should have its customer feedback or reviews?

- Strongly Agree

- Agree

- Neutral

- Disagree

- Strongly Disagree

19) I feel confident conducting business with this website?

- Strongly Agree

- Agree

- Neutral

- $\quad$ Disagree

- Strongly Disagree

Security:

20) Is the security of these websites important for you?

- $\quad$ Strongly Agree

- $\quad$ Agree

- Neutral

- $\quad$ Disagree

- Strongly Disagree

21) Will it affect you if they share your personal data on their website?

- Strongly Agree

- $\quad$ Agree

- Neutral

- $\quad$ Disagree

- $\quad$ Strongly Disagree

22) Which of the payment methods do you find helpful and easy when shopping on the website?

- $\quad$ Google Check Out

- Cash on delivery

- $\quad$ Credit

- Debit Card

- Paypal

23) The information on this website is valuable?

- $\quad$ Strongly Agree

- $\quad$ Agree

- Neutral

- Disagree

- Strongly Disagree 